\title{
Tourism as a tool of community development: an ecotourism project in Cantanhez, Guinea-Bissau
}

\author{
F. Oliveira ${ }^{1,2}$ \& F. Silva $a^{1,3}$ \\ ${ }^{1}$ School of Tourism and Maritime Technology, \\ IPL-Polytechnic Institute of Leiria, Portugal \\ ${ }^{2}$ Research Center for Identity(ies) and Diversity(ies), \\ IPL-Polytechnic Institute of Leiria, Portugal \\ ${ }^{3}$ Tourism Research Group (GITUR), \\ IPL-Polytechnic Institute of Leiria, Portugal
}

\begin{abstract}
In recent decades the scientific community and various international organizations have provided a range of guidelines towards the development of more sustainable tourism.

The responsible use of natural and cultural resources and the participation of local communities - with the involvement of the different actors in the development process - are inseparable aspects of sustainability's concept. However, when we try to put it into practice it appears that this is a very slow process, with many aspects that must be considered, especially in the case of underdeveloped regions.

This paper focuses precisely on one of these regions - Cantanhez National Park, Guinea Bissau. This region has natural and cultural resources that are real treasures, which enhance the environmental and green forms of tourism; however, the structural problems of the country can be a real challenge to any type of initiative.

The purpose of this communication is to present the ecotourism project in Cantanhez National Park, identifying the objectives, the first stages of the project implementation, the difficulties arising from the social, economic and political situation of the country and finally, its relevance in promoting community development. The realities that will be shared in this paper resulted from an
\end{abstract}


initial visit to identify the needs of tourism planning, management and training in the communities directly involved.

Keywords: ecotourism, community involvement, local community, sustainable development, training sessions.

\section{Introduction}

This paper focuses on the product Ecotourism, which is beginning to be created in Cantanhez National Park, Guinea-Bissau. This is an initiative that results from a partnership between two NGOs - the Marquês de Valle Flôr Institute (Portugal) and AD - Action for Development (Guinea-Bissau) - and has its roots in U'Anan Project - Building Sustainable Development in the region of Tombali: Ecotourism and Citizenship.

The main objective of this project is to improve the living conditions of the population of the region through the creation of a tourism product based on the maximum community involvement in this activity. In fact, the product Ecotourism in Cantanhez has great potential not only for its richness and diversity of fauna and flora, but also the cultural diversity that can be found in each tabanca. In addition, the high interest and motivation of the population to receive visitors appears to be fundamental to the development of that product in the region. This is the main reason for the participation of the Polytechnic Institute of Leiria, with its experience in the field of training in tourism and the management of infrastructure and tourist destinations.

Our cooperation is focused on training local communities in areas of tourism and hotel management. At the same time we have provided some assistance in terms of management, tour operations and advertising and tourist information tools.

This project, by the way it is structured and the principles on which it is based, is consistent with the concept of community-based ecotourism, which is supported by the World Wildlife Fund (WWF). In this context, our methodological approach is based on the list of guidelines advocated by the WWF for the development of community-based ecotourism and it is intended to identify the stage that the project of Ecotourism in Cantanhez has reached. Therefore, the aim of this paper - besides presenting the project - is to expose our role as trainers and to identify to what extent the WWF's guidelines are being met. In addition, we identify what has been accomplished, the main difficulties encountered and what we consider to be the phases of the project and the main challenges for achieving them. In addition, we give our desires and questions regarding how best to implement them and to overcome some obstacles.

\section{Ecotourism: a means to a more sustainable tourism}

The current scenario of development is characterized by unsustainable levels of consumption and harmful uses that prevent genuine renewal of natural resources and the environment, putting at risk continuity. In this context, the international political agenda has marked in recent decades the path towards a more 
sustainable development. The concerns are extended to all sectors, including tourism. In 1999, the Global Code of Ethics for Tourism highlighted tourism as a factor to sustainable development since, among other conditions, all actors in tourism development assume a duty to protect the environment and natural resources, with a view to healthy, continuous and sustainable economic growth, which is able to meet equitably the needs and aspirations of the present and future (WTO [1]).

In the same document, it was stated that "Nature tourism and ecotourism are recognized as being particularly conducive to enriching and enhancing the standing of tourism, provided they respect the natural heritage and local populations and are in keeping with the carrying capacity of the sites" [2].

Ecotourism is a type of tourism and a responsible way to develop leisure activities in natural environments that is concerned mainly with environmental conservation (to ensure biological diversity, maintenance of ecological systems) and local community welfare (TIES [3]).

Currently, sites whose main attraction are natural resources- like protected areas, forest land, islands, mountains, lakes, environmental reserves - are increasingly attractive in terms of a tourist experience. The actual scenario in which is defended the need for more sustainable ways of developing tourism, tourism demand itself has been transformed, revealing preferences for new destinations, new forms of tourism and manifesting a new approach for the places visited. With regard to new destinations, Christ et al. [4] state: "... tourism has been growing and increasing particularly in biodiversity hotspots ...". Compared with the growth in tourism demand in 2004, the global demand for ecotourism and nature tourism grew 3 times faster (WTO [5]).

Although ecotourism embrace the principles of sustainable development, it should not be confused with the concept of sustainable tourism, since it is an explicit tourism product. In any event, as emphasized by the Declaration on Ecotourism Quebec (2002), some forms of tourism, especially ecotourism can contribute to the balanced and sustainable use of natural resources, cultural and human resources in certain locations.

More specifically, ecotourism due to the physical and human characteristics of the territories where it is developed may:

- Contribute to the creation of economic benefits within the indigenous communities;

- Ensure the conservation of natural resources and cultural integrity of communities;

- Encourage community involvement and interest in conservation issues; and

- Promote visitors awareness with regard to the importance of natural and cultural heritage.

Moreover, the fact that these territories join natural wealth with a unique cultural diversity helps to promote and enhance this heritage - myths, stories, traditional activities, know-how, crafts, traditions and sustainable practices. Moreover, often these areas are inhabited by rural and extremely poor communities, with serious problems in terms of health, education, accessibility (roads and communication), and other infrastructure needed for proper 
development. In these cases, and in the first instance, the development of any activity of (eco) tourism should make an effort to resolve these problems.

\section{Ecotourism based on the involvement of local communities}

"Further massive growth is predicted for tourism between now and 2020, providing excellent opportunities for spreading prosperity but presenting considerable challenges and potential threats to the environment and local communities if not well managed. (...)There is also an increasing appreciation of the potential role of tourism in addressing world poverty, by bringing sources of income to the heart of some of the poorest communities." (WTO \& UNEP [6]).

Conventional approaches related to sustainable forms of tourism strengthen the idea of the importance of involving local communities in the process of tourism development. This involvement includes their participation in the planning stage, the occupation of jobs in tourist facilities and incentives for the development of local productions associated with traditional activities (such as agriculture, fishing, crafts). In a more ambitious perspective Swarbrooke [7] argues that local communities must take a proactive role, acting directly in the tourist market. In the field of tourism, direct participation can be associated with the creation of offers of accommodation, restaurants, commercial spaces for production and sale of agricultural products and handicrafts, the provision of information services, transportation and tour guide, organization entertainment activities and environmental interpretation, among others.

According to the World Wide Fund for Nature [8] this involvement can take different forms, including:

- The creation of private tourism businesses that employ local people (in these cases it is important to ensure adequate training to the individual tasks and to practice a policy of fair wages, avoiding situations of exploitation);

- The production of traditional crafts and other local products that are sold directly to tourists by the artisan and / or are sold to different places and tourist facilities;

- The creation of tourism infrastructure (local or developed by foreign entrepreneurs) that provide the granting of certain services to local, in exchange for a percentage of revenue;

- The existence of elements of local communities to develop their small business, individual or family;

- The creation of companies that are owned or community management. In these cases there could be a lack of organization and capacity to respond effectively to the demands of the tourist market.

Despite economic gains, social and cultural factors that may result from direct involvement of local communities, in practice, there may be many obstacles and difficulties in its operation. If, on one hand, it can be relatively easy to perceive the positive aspects of tourism and the contributions - mainly economic - they can take from tourism development, on the other, is more difficult to move to the stage of providing a tourist service. The lack of training, knowledge and capacity 
Table 1: Guidelines for community-based ecotourism development.

1. Considering the potential conservation gain

2. Checking the preconditions for ecotourism

3. Adopting an integrated approach

4. Finding the best way to involve the community

5. Working together on an agreed strategy

6. Ensuring environmental and cultural integrity

7. Ensuring market realism and effective promotion

8. Putting forward quality products

9. Managing impacts

10. Providing technical support

11. Obtaining the support of visitors and tour operators

12. Monitoring performance and ensuring continuity

Source: WWF International [8].

investment are some of the obstacles, especially if we are talking about underdeveloped regions.

Due to the numerous difficulties and challenges related with the creation of community-based ecotourism, Table 1 presents a set of guidelines that can contribute to a more organized and inclusive development.

More generally, one of the priorities of community-based ecotourism is that generated flows contribute to balance environmental, economic and human development of these sites. Although this is generally a small-scale tourism, it presents many delicate issues that must be carefully managed. The challenges are not only related with nature conservation needs, but more by the socio-economic reality of local communities. In any case, there must be a clear understanding about the relationship that must be established between local communities and conservation and how it can be improved through ecotourism. Before developing this type of tourism should be assessed whether site conditions are suitable and if they meet the essential preconditions for its development. Furthermore, ecotourism projects, to be implemented, must be articulated with other programs for conservation and sustainable development. The type and scale of these projects should conform to the characteristics of natural resources and cultural heritage and should meet the preferences and expectations of communities. For these, and because they have often a total lack of information for tourism demand, it's needed effective structures to allow their intervention and ensure benefits achievement. Also in this field, the communities will need continued access to training, advice and support the development, management and marketing of the product created.

All ecotourism products should provide high quality experiences and be subject to a management plan properly structured. Moreover, these experiences must involve media awareness of visitors and tour operators on issues related to conservation and the host community, and should include mechanisms for their support. 
Finally, and because these projects must be conceived and built within an integrated and long-term strategy, it is essential to engage the various stakeholders. The relationship between residents, government entities and/or local authorities, tour operators, NGOs will identify the role of each of the players, ensure the commitment made by each of them and, especially, in many cases, help the communication process.

\section{Ecotourism in Cantanhez: a toll for community development}

Project U'Anan - Building Sustainable Community Development in the region of Tombali: Ecotourism and Citizenship emerges, through a partnership between nongovernmental organizations (NGOs) IMVF and AD with the support of the Portuguese Institute for Development Support (IPAD) and co-financing from the European Commission. A little later comes the IPL as an element of cooperation in the areas of tourism and hotel management.

For the IMVF the main objective of this project is to improve the living conditions of all people in the region of Tombali (Guinea-Bissau), through the focus on sustainable human, social, cultural and economic developing (Brito [9]).

In socio-cultural level is intended to implement measures to promote access to safe drinking, but also improvements in health conditions, and sociability and solidarity by encouraging the channels of communication and development, thereby enhancing self-esteem and community citizenship. In the economic level the aim is to promote regular production in the primary sector as a stimulus for the development of sustainable marketing channels to ensure the increase of household incomes [8].

With economic and environment importance arises Ecotourism Project as one of the major points of U'Anan in a quest for greater economic growth and preservation of forests and conservation of endangered species in the area of project implementation. With these objectives are in progress a series of crucial measures:

- Construction of means of accommodation and support infrastructures such as a restaurant and bar;

- Creation of a museum near the ruins of an old fort in Guiledje;

- Awareness of communities to a bigger attention to hygiene and waste treatment, and also for a harmonization of environmental resources and the prominent needs of the population;

- Training for members of the community in the area of hotels and restaurants (the host service, table service, planning and preparation of meals, cleaning) and tourism (training of nature guides, preparation of content associated with environmental interpretation and environmental routes, technical monitoring and groups management);

- Identification of activities which complement the tourism product (traditional activities such as handicraft, production and processing of agricultural products, honey production, fishing, boating and biking, among others); 


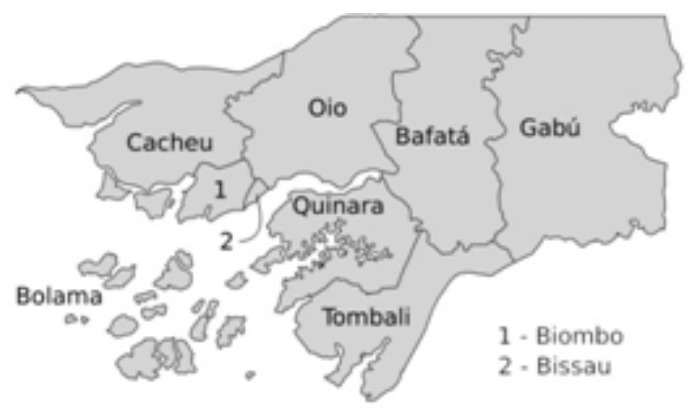

Figure 1: Map of Guinea-Bissau, by regions. Source: www.republicaguineabissau.org [10].

- Preparation of various package tours in order to market this tourism product either directly or through intermediaries (Travel Agencies and Tour Operators).

Basically, the aim of this project is to use a series of tools enabling a more widespread and "decrease distance" for the region of Tombali in seeking to create conditions for sustainable community development of the population.

Guinea-Bissau is located in Africa more specifically on the west coast of this continent. It is bordered to the south with Guinea and Senegal to the north. The country has about $36,500 \mathrm{~km}^{2}$ and 1.5 million inhabitants and is divided into 8 regions (Bolama, Cacheu, Gabu, Bafata, Quinara, Oio, Biombo and Tombali) and an independent sector which is Bissau (Figure 2).

The Tombali region is located in southern Guinea-Bissau bordering the north of Guinea, distant about 250 kilometres from the capital - Bissau.

It is an area of about 86,850 inhabitants spread over 5 areas: Bedanda, Catio, Komo, and Quebo Cacine and 13 tabancas. The ecotourism project focuses on Bedanda and Cacine sectors where we can find Cantanhez Forest, the most important area of cooperation. The Cantanhez Forest is an area with an enormous richness in fauna and flora, preserved due to the distance and isolation from major urban centres. However, beyond the ecological value Tombali also has historical value since it was the "cradle of Guinean nationality" as seen through the still present traces of the struggle of national liberation.

From a socio-cultural perspective, and as in general throughout the country, this region is characterized by a diversity of ethnic groups, marked by the particularities of each group that are reflected in the forms of social life. We refer to aspects such as planning, construction methods and materials, religious beliefs and rituals, gastronomy, handicraft production and other productive activities with economic value. The main ethnic groups in the country are: Balanta, Fula, Manjaca, Mandingo, Papel, Felupe, Mancanhas, Bijagos Nalu and Beafada. In Tombali region the predominant ethnic group is Nalu, but Fula and Balanta are also important.

The ethnic lines strongly marked carry a great diversity in form of music, ways of life, work tools and social organization of tabancas, which may be important in this project. With an important role in Guinea-Bissau culture we 
have also the gastronomy, which is rich in nutrients and favours the use of local products

In Cantanhez region, agriculture and collection of forest and marine products are the basis of livelihood of residents. The extraction of palm products, particularly palm oil and Cibi wine are important, such as the rice crop, cultivated by most households. The rice produced is intended solely for consumption by the population. Now however with an increasing expression, are the nuts and peanuts cultures, not only for the agricultural holding, but also for household income and extreme importance in the country trade balance. The fishing activity is also common in Cantanhez. Although initially seen as a means of subsistence, with the presence of foreign fishermen have been seized new techniques that will allow some fishermen to get some income.

Looking for other sources of income are already built some means of accommodation and additional services in Iemberém, Faru Sadjuma. On the way Bissau - Cantanhez tourists may wish to spend a few days in Faru Sadjuma, since this is small tabanca between the capital and Iemberém (main tourism area of Cantanhez), where the main activity is agriculture (orange, tangerine, pineapple ...), with a very friendly population that allows a huge cultural and social contact.

In the specific case of Iemberém, area of highest incidence of cooperation, the tourist hub consists in:

- Three bungalows:

- Two passing houses, with two bedrooms (two beds) each and sanitary facilities;

- A restaurant-bar.

Our cooperation in this project involves a total of three visits to Tombali and is related to consulting and training in ecotourism and hospitality. At this point have been carried out two visits (one in 2009 and the last in 2010) whose main objectives were the recognition of the impact area of the project and identification of training needs in the local communities that will ensure the project implementation, in a more operational component (i.e., reception and accommodation of tourists, housekeeping, Food \& Beverage (F\&B) and tourists monitoring in terms of ecotourism activities). Furthermore, it was planned and administered a series of training actions for different groups of people who will ensure the operational component. In methodological terms, we decided to have first a complete observation of the infrastructures, ecotourism activities and human resources involved, followed by an identification of priority needs in training.

We also tried, through lectures to all the leaders of the tourism centres in Cantanhez National Park, to explain the procedures in care and supervision of the guest, but also in restaurants, more specifically in the constitution of the menus of the several meals and table service to be implemented. In addition we approached the housekeeping operations and management, were the ladies who previously had the training, demonstrated to all the others the cleaning process of a housing unit. At the end we tried to explain hospitality industry in a global context and highlighted the strengths to be explored by the communities and the ways to fight the existing weaknesses. 
At the same time, we identified new possibilities of participation of others members of the community on this project so that they may help to improve it. On the other hand, this participation may contribute to enlarge the sustainability of the project by increasing other economic activities, like trade. Such relationships already exist, especially in the restaurant area, where the person responsible by the kitchen, buys products to other elements in the community and hires staff to help her in the kitchen and to perform the table service.

Still, we believe that these relationships can and should be extended to other elements of the community through activities in the region that may complement the tourist experience. We emphasize, for example, crafts, production of jams and palm oil, , the extraction of Cibi wine, monitoring of traditional activities such as rice mill, processing of cassava into various products and harvesting and preparation of cashew nuts and peanuts for gastronomy use.

These activities are directly linked to local "know-how" and traditional agricultural practices, but they also can be used to occupy the free time that tourists have between ecotourism activities, and to give him a wide range of traditional products that can be bought.

\section{Conclusion}

The Guinea-Bissau, and particularly the region of Cantanhez, has natural, human and cultural resources wealth with important value in terms of environmental tourism. Projects such as the ecotourism in Cantanhez may be an opportunity to boost the local communities economically and to promote and disseminate the cultural and natural values.

The mere fact that it is a country with many development problems can place many barriers to the implementation of a project like this. Despite the limitations, the current level of tourism development demonstrates how this activity can help to improve the social and economic dynamics of these vulnerable communities. Moreover, on tourist demand side, there's a large travel development to destinations that provide unique experiences based on direct contact with the people visited and the different expressions of their culture and their traditional activities.

Reflecting on the implementation of this project (since the involvement of different partners, financial support demand and the integration of communities through implementation in the field of infrastructure and tourism-related activities), it seems that even so unconscious, were followed most of the guidelines that can contribute to the development of community-based ecotourism (table 1). In Tombali some of these guidelines have been followed in some way. Before the implementation of this project was a preliminary study conducted by Brígida Brito that demonstrate the potential of the destination for ecotourism, also focusing on the benefits this may bring to environment conservation. A major concern (and objective) of this project was always to have an integrated approach in an attempt to involve the most of the communities, not only for those who are close to the area of impact, but also for the farthest that can provide other services (e.g. transport). 
In order to achieve a total community involvement, operations and management of tourism hubs is totally entrusted to the local population in close collaboration with $\mathrm{AD}$, although in this case and as already mentioned, there is small participation of other members of the community especially the field of handicrafts, traditional and leisure activities.

The main difficulties begin to arise when trying to work together on a common and shared strategy and maintain the environmental and cultural integrity. There are great difficulties in achieving common objectives for the whole population, because there are a lack of knowledge of tourism requirements and eco tourist needs. The situation in the country, where subsistence is difficult, also makes the pursuit of common objectives. This subsistence difficulty also limits the environmental integrity, as the craving to earn some money can lead to carelessness and lack of concern with environmental issues.

The other guidelines are currently being developed in conjunction with the community, responsible organizations and key partners in this activity. The demand for specific tourism markets and the consequent promotion is already being hatched by the development of a website and at the same time seeking to create tour packages tailored to the needs of ecotourism demand. In this field, we have already started contacts to search support and partnerships with other tourism organizations and hotels in Guinea-Bissau in order to achieve better and more reliable touristic product. However there are many aspects related with conception and management of a tour package that must be worked out.

The impacts are being managed and controlled in its various forms: social (and cultural), economic and environmental through the analysis of tourism activity and its repercussions since the beginning of the project. This analysis also aims to monitor performance and ensure the future by checking the satisfaction of tourists that is currently provided through questionnaires on the spot.

One of the biggest challenges of this project is never forget that we are dealing with a culture that has very distinct characteristics from the Western culture. The organization, the interests and the rhythms of life are very singular. Moreover, tourism is a completely new area for these people, which requires a set of procedures in services provision which must be slowly introduced. In operational terms, the contact with tourists should be carefully thought out. Despite the total number of beds does not allow the reception of large groups, yet a first step, it should be to plan very well the number of tourists who will visit those communities and the frequency with which they may come. This is a main point if we want to guarantee the well-being of local community, maintain the environmental balance and maximize visitor's experience.

\section{References}

[1] WTO, Global Code of Ethics for Tourism. Resolution /RES/406(XIII) XIII General Assembly of the World Tourism Organization: Santiago de Chile, 1999. URL: www.world-tourism.org/code_ethics/eng.html. 
[2] http://www.worldtourism.org/sustainable/IYE/quebec/anglais/declaration.ht $\mathrm{ml}$

[3] TIES, TIES Global Ecotourism Fact Sheet: Washington DC, 2006. URL: www.ecotourism.org.

[4] Christ, C., Hillel, O., Matus, S. e Sweeting, J., Tourism and Biodiversity Mapping Tourism's Global Footprint: Washington, DC: CI-Conservation International /UNEP, pp.4, 2003.

[5] WTO, WTO Press release, June 2004.

[6] WTO \& UNEP, Making Tourism More Sustainable - A Guide for Policy Makers, WTO \& UNEP: France/Spain, pp. 2005.

[7] Swarbrooke, J., Sustainable Tourism Management, Cab International: UK, 1999.

[8] WWF International, Guidelines for community-based ecotourism development, WWF-UK: UK, 2001.

[9] Brito, B., Estudo das Potencialidades e dos Constrangimentos do Ecoturismo na Região de Tombali. Desenvolvido no âmbito do Projecto U'Anan - Construir o Desenvolvimento Comunitário Sustentável na Região de Tombali: Ecoturismo e Cidadania. Instituto Marquês de Valle Flor/Acção para o Desenvolvimento, 2007.

[10] Guinea-Bissau Republic, www.republicaguinea-bissau.org 